\title{
Rancang Bangun Klasifikasi Cacat pada Genting Menggunakan Metode Support
} Vector Machine (SVM)

\section{Design and Development Classifications A Defect in Clay Tiles Using A Method of Support Factor Machine (SVM)}

\author{
Rais Yufli Xavierullah ${ }^{* 1}$, Murman Dwi Prasetio ${ }^{1}$, Denny Sukma Eka Atmaja ${ }^{1}$ \\ ${ }^{1}$ Prodi S1 Teknik Industri, Fakultas Rekayasa Industri, Universitas Telkom
}

ARTICLE INFO

Article history:

Diterima 04-09-2020

Diperbaiki 15-12-2020

Disetujui 29-12-2020

Kata Kunci:

Genting Tanah Liat, Support

Vector Machine, Image

Processing

\begin{abstract}
A B S T R A K
Pengendalian kualitas merupakan suatu sistem yang dapat membantu suatu perusahaan dalam menjaga dan mempertahankan kualitas produk agar tidak adanya terjadi cacat produk. PT. XYZ merupakan salah satu perusahaan yang berada pada bidang industri genting tanah liat. Pada setiap bulannya PT. XYZ memiliki pengembalian produk karena cacat dengan rata-rata 2225 genting. Salah satu masalah yang terjadi pada PT. XYZ yaitu proses inspeksi yang hanya mengunakan penglihatan. Penggunaan penglihatan dapat memiliki risiko seperti peningkatan biaya operasi karena pemeriksaan yang salah, kegagalan mendapatkan bisnis, dan pengerjaan ulang. Dengan perkembangan tekhnologi dapat mengatasi hal tersebut dengan ditemukannya pendeteksi bersifat buatan dengan menggunakan metode pengukuran, preprocessing gambar, dan algoritma dalam mendeteksi cacat tersebut. Pada penelitian ini menggunakan metode Support Vector Machine (SVM) dalam melakukan pengklasifikasian cacat. Pengambilan gambar secara langsung pada penelitian ini menggunakan raspberry pi dan pembuatan sistem algoritma menggunakan software pyhton. Penelitian ini menggunakan kernel linear pada algoritma SVM. Hasil pada penelitian ini menyimpulkan bahwa tingkat akurasi tertinggi yaitu 88,6\% dengan menggunakan kernel linear.
\end{abstract}

Keywords:

Clay Tile, Support Vector

Machine, Image Processing

\section{A B S TR ACT}

Quality control is a system that can assist a company in maintaining and maintaining product quality so that product defects do not occur. PT. XYZ is a company in the clay tile industry. Every month, PT. XYZ has products due to defects with an average of 2225 precarious. One of the problems that occurred at PT. $\mathrm{XYZ}$ is an inspection process that only uses sight. The use of sight can carry the risk of increased operating costs due to faulty examinations, failure to get business, and rework. With the development of technology, it can overcome this problem by finding artificial detectors using measurement methods, image preprocessing, and algorithms to detect defect. In this study using the Support Vector Machine (SVM) method in classifying defects. Taking pictures directly in this study using raspberry pi and making the algorithm system using pyhton software. This study uses a linear kernel in the SVM algorithm. The results in this study concluded that the highest accuracy rate was $88.6 \%$ using a linear kernel.

\section{Pendahuluan}

Pengendalian kualitas merupakan suatu sistem yang dapat membantu suatu perusahaan dalam menjaga dan mempertahankan kualitas produk agar tidak adanya terjadi cacat produk [1]. Bila mana pengendalian kualitas tidak sesuai dengan standarnya dapat berakibat produk cacat yang akan menyebabkan konsumen tidak puas dan dapat menjadikan pelanggan menggunakan produk perusahaan tesebut [2].
PT.XYZ merupakan salah satu perusahaan yang berada pada bidang industri genting. PT.XYZ memiliki pengklasifikasian produk yaitu bagus, cacat batu putih, cacat retak seperti pada Gambar 1. Klasifikasi merupakan salah satu pendekatan dari data mining dengan cara membuat suatu model yang sebagai tujuan dalam mengelompokkan objek yang memiliki ciri-ciri yang sama ke dalam suatu kelas yang telah ditentukan [3]. Pada setiap bulannya PT. XYZ memiliki pengembalian produk karena cacat dengan rata-rata 2225 
genting. Salah satu masalah yang terjadi pada PT. XYZ yaitu proses inspeksi yang hanya mengunakan penglihatan. Penggunaan penglihatan dapat memiliki risiko seperti peningkatan biaya operasi karena pemeriksaan yang salah, kegagalan mendapatkan bisnis, dan pengerjaan ulang [4]. Dengan perkembangan tekhnologi dapat mengatasi hal tersebut dengan ditemukannya pendeteksi bersifat buatan dengan menggunakan metode pengukuran, preprocessing gambar, dan algoritma dalam mendeteksi cacat tersebut [5].

Tabel 1.

Tipe Genting

\begin{tabular}{|c|c|c|}
\hline Nomor & Tipe Genting & Gambar \\
\hline 1 & Bagus & \\
2 & Batu Putih & \\
\hline 3 & & \\
\hline
\end{tabular}

Salah satu metode yang digunakan dalam pengklasifikasian adalah Support Vector Machine (SVM). SVM sering digunakan karena memiliki kemampuan untuk menemukan yang memiliki sifat global optimal dan juga dapat melakukan pengklasifikasian untuk suatu pattern [6]. Berdasarkan hal tesebut penulis akan melakukan penelitian mengenai pengklasifikasian genting dari genting yang bagus, genting cacat batu putih, genting cacat retak dengan mengggunakan metode Support Vector Machine (SVM) yang dapat membantu dalam meningkatkan akurasi dalam pengklasifikasian genting.

\section{Landasan Teori}

\subsection{Kualitas Genting}

Terdapat tingkat mutu suatu genting tanah liat pada permukaan [7]. Kualitas mutu 1 mempunyai permukaan yang utuh, kerapatan dalam pemasangan yang baik, warna yang sama dengan keseluruhan genting dan memiliki suara yang nyaring. Tingkat mutu 2 mempunyai kualitas dengan permukaan yang utuh dan pada genting itu sendiri memiliki kerapatan dalm pemasangan yang baik. Tingkat mutu 3 bila dilihat dari permukaan genting terdapat cacat-cacat yang sedikit, terdapat retakan yang sedikit pada genting, dan kerapatan dalam pemasangan genting cukup baik. Pada tingkat mutu 4 bila dilihat dari permukaan terdapat cacat-cacat pada genting yang tidak terlalu besar, sedikit retak-retak, dan kerapatan pada pemasangan cukup baik. Tingkat mutu 5 terdapat cacat-cacat dan retak tetapi masih bisa dipakai.

\subsection{Pengolahan Citra Digital}

Pengolahan citra adalah berbagai teknik yang digunakan untuk memanipulasi dan memodifikasi citra dengan berbagai cara. Sebagai contohnya adalah foto yang bergambar dua dimensi dan dapat diolah dengan mudah. Setiap foto dalam bentuk citra digital (misalnya berasal dari kamera digital) dapat diolah melalui perangkat-lunak tertentu. Sebagai contoh, apabila hasil bidikan kamera terlihat agak gelap, citra dapat diolah agar menjadi lebih terang. Terdapat kemungkinan dalam pemisahan foto orang dengan latar belakangnya. Gambaran tersebut menunjukkan hal sederhana yang dapat dilakukan melalui pengolahan citra digital [8].

\subsection{Citra Berwarna}

Citra berwarna, atau yang biasa disebut citra RGB, merupakan jenis citra yang menyajikan warna dalam bentuk komponen R (merah), G (hijau), dan B (biru) seperti pada. Setiap komponen warna menggunakan 8 bit (nilainya berkisar antara 0 sampai dengan 255) seperti yang dilihatkan dalam tabel 2. Dengan demikian, kemungkinan warna yang bisa disajikan mencapai 255 × 255 × 255 atau 16.581 .375 warna [9].

Tabel 2.

Warna dan Nilai Penyusun

\begin{tabular}{cccc}
\hline Warna & R & G & B \\
\hline Merah & 255 & 0 & 0 \\
Hijau & 0 & 255 & 0 \\
Biru & 0 & 0 & 255 \\
Hitam & 0 & 0 & 0 \\
Putih & 255 & 255 & 255 \\
Kuning & 0 & 255 & 255 \\
\hline
\end{tabular}

\subsection{Citra Berskala Keabuan}

Sesuai dengan namanya, citra jenis ini menangani gradasi warna hitam dan putih, yang akan menghasilkan efek warna abu-abu seperti pada. Pada jenis gambar ini, warna dinyatakan dengan intensitas. Intensitas yang terjadi berkisar antara 0 sampai dengan 255. Dengan nilai 0 menyatakan hitam dan nilai 255 menyatakan putih [8]. Citra grayscale sendiri diperoleh dengan melakukan konversi citra RGB. Terdapat tiga buah teknik konversi, yaitu [10].

\subsection{Support Vector Machine (SVM)}

Algoritma Support Vector Machine (SVM) merupakan sebuah metode yang pertama kali diperkenalkan oleh Vapnik. SVM sering digunakan karena memiliki kemampuan untuk menemukan yang memiliki sifat global optimal [8]. Pada SVM sendiri hanya menyimpan sebagian kecil data latih untuk digunakan pada saat prediksi c. Pencarian hyperplane terbaik yang berfungsi sebagai pemisah dua buah kelas data pada input space termasuk konsep klasifikasi dengan SVM Pada Gambar 2.4 memperlihatkan beberapa data yang merupakan anggota dari dua buah kelas data yakni +1 dan -1 . Kelas -1 digambarkan simbol data yang berbentuk lingkaran, 
sedangkan kelas +1 digambarkan simbol data yang berbentuk bujung sangkar.

Hyperplane pemisah terbaik antara kedua kelas tersebut dapat ditemukan dengan mengukur margin hyperplane dan mencari titik maksimalnya. Jarak antara hyperplane tersebut dengan data terdekat dari masing-masing kelas adalah margin. Data yang paling dekat inilah yang disebut dengan support vector. Hyperplane terbaik terletak di tengah-tengah kedua kelas. Support vector disini adalah data lingkaran dan bujur sangkar yang dilewati garis putus-putus (garis batas margin) [11]. Support Vector Machine (SVM) menggunakan model linear sebagai decision boundary dengan bentuk umum sebagai berikut:

$\mathrm{y}(\mathrm{x})=\mathrm{wT} \emptyset(\mathrm{x})+\mathrm{b}$

Dimana vektor input disini adalah $\mathrm{x}$, parameter bobot adalah w, fungsi basis adalah $\emptyset(\boldsymbol{x})$, dan suatu bias adalah $\mathrm{b}$. Bidang pembatas pertama membatasi kelas pertama sedangkan bidang pembatas kedua membatasi kelas kedua. sehingga diperoleh [3]:

$\mathrm{xi} . \mathrm{w}+\mathrm{b} \geq+1$ untuk $\mathrm{yi}=+1$

$\mathrm{xi} . \mathrm{w}+\mathrm{b} \leq-1$ untuk yi=-1

w adalah adalah normal bidang dan $b$ adalah posisi bidang relatif terhadap pusat koordinat.

Penggunaan SVM sendiri dikenal dengan menggunakan beberapa kernel yang digunakan untuk masalah bersifat nonlinear. Data yang digunakan akan diproyeksikan ke dimensi yang lebih tinggi sehingga dapat membantu dalam melakukan pemisahan. Adapun dalam penelitian kali ini akan menggunakan tiga kernel sebagai bahan penelitian yaitu linear, polynomial, rbf dengan rumus sebagai berikut[12]:

$$
\begin{aligned}
& \text { 1. Linear: } \\
& K(x, y)=x y
\end{aligned}
$$

$$
K(x, y)=(x, y+c)^{d}
$$

$$
\begin{aligned}
& K(x, y)=\exp \left(y\|x-y\|^{2}\right) \\
& \text { Keterangan: } \\
& K=\text { Kernel } \\
& x, y=\text { Dot product } \\
& \mathrm{c}=\text { Konstanta } \\
& \mathrm{d}=\text { Degree of kernel } \\
& \gamma \quad=\text { Gamma }
\end{aligned}
$$

\section{Metode Penelitian}

\subsection{Objek Penelitian}

Genting tanah liat merupakan objek dari penelitian ini. Gambar genting yang diambil dilakukan secara tidak langsung sebagai data latih dan data uji penelitian. Jenis-jenis yang diteliti adalah genting bagus, genting cacat retak, genting cacat batu putih. Objek penelitian dapat dilihat pada Gambar 1.

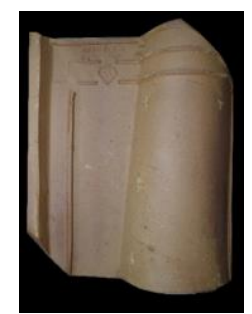

(a)

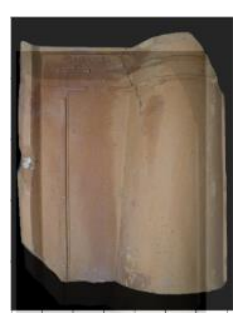

(b)

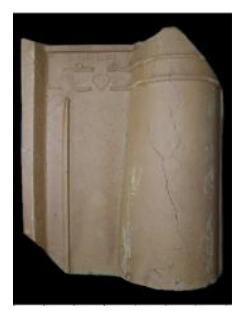

(c)
Gambar 1 Objek penelitian (a) bagus, (b) cacat batu putih, (c) cacat retak

\subsection{Metode Penelitian}

Tujuan dari penelitian ini adalah untuk merancang bangun dalam pengklasifikasian cacat yang terjadi pada genting dengan menggunakan metode Support Vector Machine (SVM).

\section{a. Identifikasi Kebutuhan}

Tahap awal dilakukan dengan mengidentifikasi kebutuhan dalam mengambil gambar agar hasil gambar yang didapatkan optimal, terdapat dua parameter yang digunakan. Parameter yang digunakan berdasarkan penelitian oleh Atmaja dan Herliansyah (2015) yaitu penggunaan jarak kamera dengan objek adalah $50 \mathrm{~cm}$ dan resolusi kamera yang digunakan ialah $360 \times 480$ pixels.

\section{b. Desain Prototype}

Pada tahap ini dilakukannya perancangan desain sistem otomasi yang digunakan terdapat dua tahap yaitu membuat desain hardware dan desain software sesuai dengan pada Gambar 2.

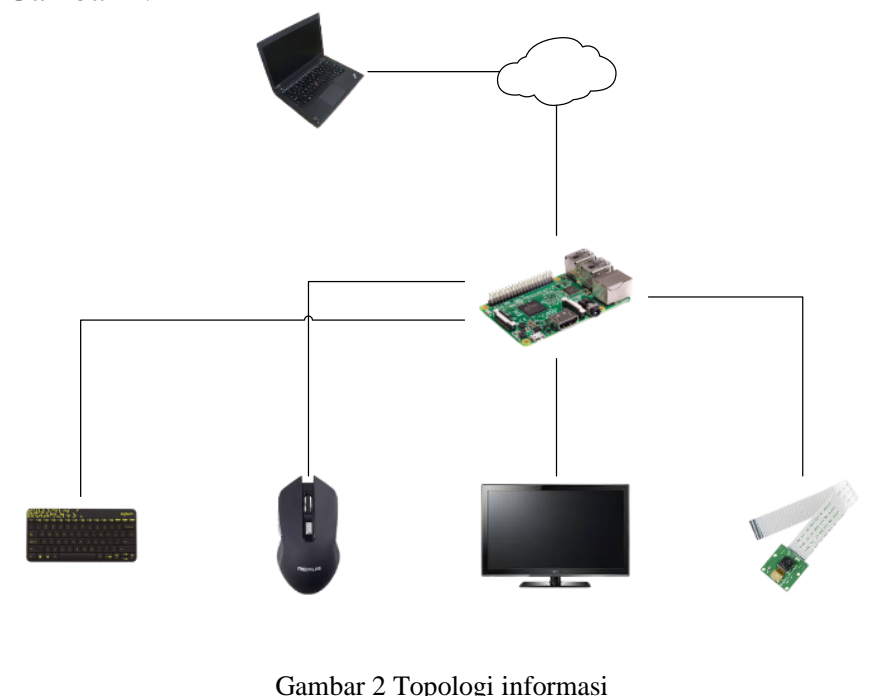

Desain hardware menggunakan parameter sesuai dengan tahap identifikasi kebutuhan yang dilakukan sebelumnya Desain software digunakan dalam penelitian ini adalah software python sebagai program utama dalam mengolah data. Software ini digunakan sebagai akuisisi gambar, preprocessing gambar, dan juga klasifikasi gambar. Pada penelitian ini menggunakan rig penelitian agar dapat menaruh kamera pada saat proses pengambilang gambar seperti pada 
Gambar 3. Ukuran dari rig penelitian disesuaikan dengan proses sebelumnya yaitu identifikasi kebutuhan

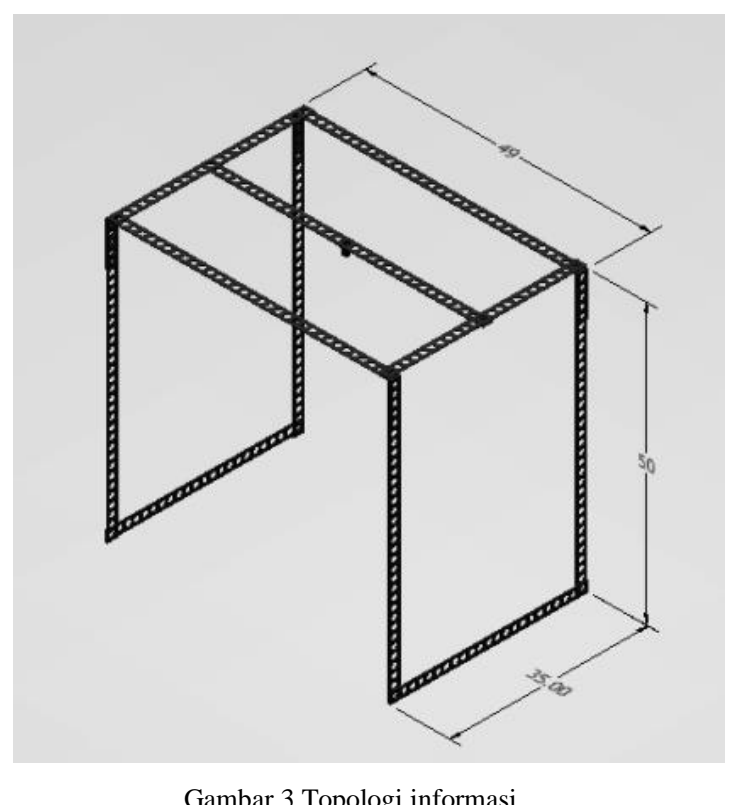

\section{c. Klasifikasi Support Vector Machine (SVM)}

Pada tahap ini data yang sudah didapatkan akan dilipatgandakan dengan mengaugmentasi data sebesar 3 kali dari dataset sebelumnya agar mendapatkan akurasi yang lebih baik. Selanjutnya dilakukan pembagian data menjadi dua yaitu data latih dan juga data uji. Setelah pembagian, dilakukannya pengklasifikasian dengan menggunakan algoritma Support Vector Machine dan menentukan jenis cacat. Tugas klasifikasi biasanya melibatkan pemisahan data ke dalam data pelatihan dan pengujian yang sudah dilakukan, data latih sendiri akan dipelajari oleh algoritma SVM yang akan menjadi referensi utama dalam pengklasifikasian. Data latih ini akan dijadikan sebagai model pengklasifikasian. Kernel yang digunakan pada penelitian ini adalah kernel linear, kernel rbf, kernel polynomial.

Tabel 3 .

Pembagian Data Latih dan Data Uji

\begin{tabular}{lccc}
\hline \multicolumn{1}{c}{ Kelas } & Label & Data Latih & Data Uji \\
\hline Bagus & 0 & 54 & 24 \\
Batu Putih & 1 & 62 & 28 \\
Retak & 2 & 87 & 36 \\
\hline Total Data & & 203 & 88 \\
\hline
\end{tabular}

\section{Hasil dan Pembahasan}

\subsection{Perbandingan Kernel Support Vector Machine}

Pada penelitian akan memperlihatkan hasil dari perbandingan antara beberapa kernel yang digunakan yaitu kernel linear, kernel rbf, dan kernel polynomial. Prediksi gambar genting yang digunakan akan diperlihatkan dengan menggunakan confusion matrix. Penggunaan confusion matrix dimaksud agar dapat melihat sistem yang digunakan sudah baik dalam memprediksi setiap kelasnya[13]. Confusion matrix pada kernel linear dapat dilihat melalui Tabel 4. Terdapat 24 total genting yang seharusnya kelas bagus di prediksi menjadi 17 kelas bagus, 0 kelas cacat batu putih, 7 kelas cacat retak. Terdapat 28 total genting yang seharusnya kelas batu putih di prediksi menjadi 1 kelas bagus, 26 kelas cacat batu putih, 1 kelas cacat retak. Selanjutnya terdapat 36 total genting yang seharusnya kelas cacat retak di prediksi menjadi 1 kelas bagus, 0 kelas cacat batu putih, 35 kelas cacat retak.

Tabel 4.

Confusion Matrix Kernel Linear

\begin{tabular}{|c|c|c|c|c|}
\hline \multicolumn{1}{|c}{$\begin{array}{c}\text { Correct } \\
\text { Classification }\end{array}$} & Bagus & $\begin{array}{c}\text { Cacat Batu } \\
\text { Putih }\end{array}$ & Cacat Retak \\
\cline { 2 - 5 } & Bagus & 17 & 0 & 7 \\
\cline { 2 - 5 } Actual Class & $\begin{array}{c}\text { Cacat Batu } \\
\text { Putih }\end{array}$ & 1 & 26 & 1 \\
\cline { 2 - 5 } & Cacat Retak & 1 & 0 & 35 \\
\hline
\end{tabular}

Confusion matrix pada kernel rbf dapat dilihat melalui Tabel 5. Terdapat 24 total genting yang seharusnya kelas bagus di prediksi menjadi 3 kelas bagus, 3 kelas cacat batu putih, 18 kelas cacat retak. Terdapat 28 total genting yang seharusnya kelas batu putih di prediksi menjadi 0 kelas bagus, 24 kelas cacat batu putih, 4 kelas cacat retak. Selanjutnya terdapat 36 total genting yang seharusnya kelas cacat retak di prediksi menjadi 0 kelas bagus, 4 kelas cacat batu putih, 32 kelas cacat retak.

Tabel 5.

Confusion Matrix Kernel Rbf

\begin{tabular}{|c|c|c|c|c|}
\hline \multirow{2}{*}{$\begin{array}{c}\text { Correct } \\
\text { Classification }\end{array}$} & Predicted Class \\
\cline { 2 - 5 } & Bagus & 3 & $\begin{array}{c}\text { Cacat Batu } \\
\text { Putih }\end{array}$ & Cacat Retak \\
\hline \multirow{4}{*}{ Actual Class } & $\begin{array}{c}\text { Cacat Batu } \\
\text { Putih }\end{array}$ & 0 & 3 & 18 \\
\cline { 2 - 5 } & Cacat Retak & 0 & 24 & 4 \\
\hline
\end{tabular}

Confusion matrix pada kernel polynomial dapat dilihat melalui Tabel 6. Terdapat 24 total genting yang seharusnya kelas bagus di prediksi menjadi 17 kelas bagus, 0 kelas cacat batu putih, 7 kelas cacat retak. Terdapat 28 total genting yang seharusnya kelas batu putih di prediksi menjadi 1 kelas bagus, 25 kelas cacat batu putih, 2 kelas cacat retak. Selanjutnya terdapat 36 total genting yang seharusnya kelas cacat retak di prediksi menjadi 2 kelas bagus, 0 kelas cacat batu putih, 34 kelas cacat retak.

Tabel 6.

Confusion Matrix Kernel Polynomial
\begin{tabular}{|c|c|c|c|c|}
\hline \multirow{4}{*}{$\begin{array}{c}\text { Correct } \\
\text { Classification }\end{array}$} & Bagus & $\begin{array}{c}\text { Cacat Batu } \\
\text { Putih }\end{array}$ & Cacat Retak \\
\cline { 2 - 5 } & Bagus & 17 & 0 & 7 \\
\cline { 2 - 5 } & $\begin{array}{c}\text { Cacat Batu } \\
\text { Putih }\end{array}$ & 1 & 25 & 2 \\
\cline { 2 - 5 } & Cacat Retak & 2 & 1 & 34 \\
\hline
\end{tabular}

Setelah menggunakan confusion matrix dilakukan proses menghitung akurasi seperti pada Tabel 7 menunjukkan bahwa tingkat akurasi pada tiap kernel berbeda. Untuk kernel linear memiliki akurasi 88,6\% sedangkan kernel rbf mempunyai tingkat akurasi sebesar 80,6\%, dan kernel polynomial 
memiliki tingkat akurasi sebesar 86,3\%. Tingkat akurasi terbesar yaitu kernel linear dengan tingkat akurasi sebesar $87,5 \%$.

Tabel 7

Confusion Matrix Kernel Rbf

\begin{tabular}{cc}
\hline Nama Kernel & Tingkat Akurasi \\
\hline Linear & $88,6 \%$ \\
Rbf & $67,1 \%$ \\
Polynomial & $86,3 \%$ \\
\hline
\end{tabular}

\section{Kesimpulan}

Berdasarkan hasil dari rancangan usulan tentang rancang bangun klasifikasi cacat genting dengan menggunakan klasifikasi metode SVM mendapatkan hasil akurasi dari data uji yang didapatkan dengan menggunakan kernel linear sebesar $88,6 \%$.

\section{Referensi}

[1] Ratnadi and E. Suprianto, "Pengendalian Kualitas Produksi Menggunakan Alat Bantu Statistik (Seven Tools) Dalam Upaya Menekan Tingkat Kerusakan Produk," Indept, vol. 6, no. 2, pp. 10-18, 2016.

[2] M. Musafak, J. K. Runtuk, and S. Sumartono, "Usulan Pengurangan Jumlah Cacat Part Produk Frame X," JIE Sci. J. Res. Appl. Ind. Syst., vol. 3, no. 2, p. 129, 2019, doi: 10.33021/jie.v3i2.528.

[3] S. Aprilla, M. T. Furqon, and M. A. Fauzi, "Klasifikasi Penyakit Skizofrenia dan Episode Depresi Pada Gangguan Kejiwaan Dengan Menggunakan Metode Support Vector Machine ( SVM )," J. Pengemb. Teknol. Inf. dan Ilmu Komput., vol. 2, no. 11, pp. 5611-5618, 2018.

[4] M. D. Prasetio, "An Approaching Machine Learning Model: Tile Inspection Case Study," Int. J. Innov. Enterp. Syst., vol. 4, no. 01, pp. 12-22, 2020, doi: 10.25124/ijies.v4i01.44.

[5] Z. Li, J. Zhang, T. Zhuang, and Q. Wang, "Metal surface defect detection based on MATLAB," Proc.
2018 IEEE 3rd Adv. Inf. Technol. Electron. Autom. Control Conf. IAEAC 2018, no. Iaeac, pp. 2365-2371, 2018, doi: 10.1109/IAEAC.2018.8577540.

A. M. Puspitasari, D. E. Ratnawati, and A. W. Widodo, "Klasifikasi Penyakit Gigi Dan Mulut Menggunakan Metode Support Vector Machine," J. Pengemb. Teknol. Inf. dan Ilmu Komput., vol. 2, no. 2, pp. 802-810, 2018.

I. Ari Sanjaya, "Pengaruh Jumlah Penggilingan Tanah Liat Sebagai Bahan Pembuat Genteng Terhadap Karakteristik Genteng Keramik Darmasaba," J. Ilm. Tek. Sipil, vol. 13, no. 1, pp. 82-92, 2009.

[8] Shadika, "Optimasi Klasifikasi Cacat Pada Kain Tenun Gorden Menggunakan Metode Image Processing Dan Metode Artificial Neural Network di Pt Buana Intan Gemilang," 2017.

[9] P. D. Wananda, "Perancangan Sistem Deteksi Cacat Kayu Dengan Metode Deteksi Tepi Susan Pada Pengolahan Citra Berwarna.," 2018.

[10] H. Anazmar, "Analisis Performansi Sistem Pendeteksi Kualitas Kayu Jati Menggunakan Pengolahan Citra Dengan Metode Histogram Of Oriented Gradients dan Support Vector Machine," 2019.

[11] T. F. B. Nusantara, "Klasifikasi Jenis Kulit Wajah Pria Berdasarkan Tekstur Menggunakan Metode Gray Level Co-Occurrance Matrix (GLCM) Dan Support Vector Machine (SVM)," 2018, doi: 10.1017/CBO9781107415324.004.

[12] D. Helyudanto, F. Nhita, and A. A. Rohmawati, "Prediksi Penyebaran Demam Berdarah di Kabupaten Bandung dengan Metode Hybrid Autoregressive Integrated Moving Average ( ARIMA ) dengan Support Vector Machine ( SVM )," 2019.

[13] M. D. Prasetio, T. Hayashida, I. Nishizaki, and S. Sekizaki, "Deep belief network optimization in speech recognition," Proc. - 2017 Int. Conf. Sustain. Inf. Eng. Technol. SIET 2017, vol. 2018-Janua, pp. 138-143, 2018, doi: 10.1109/SIET.2017.8304124. 